\title{
Research on Selection of Tests to Assess Students' Physical Fitness at Ho Chi Minh City University of Technology and Education (Viet Nam)
}

\author{
Thanh Nguyen Duc \\ The Center of Physical and Defense Education, Ho Chi Minh City University of Technology and Education, Vietnam
}

Received May 24, 2021; Revised August 5, 2021; Accepted August 27, 2021

\section{Cite This Paper in the following Citation Styles}

(a): [1] Thanh Nguyen Duc, "Research on Selection of Tests to Assess Students' Physical Fitness at Ho Chi Minh City University of Technology and Education (Viet Nam), "International Journal of Human Movement and Sports Sciences, Vol. 9, No. 5, pp. 981 - 992, 2021. DOI: 10.13189/saj.2021.090520.

(b): Thanh Nguyen Duc (2021). Research on Selection of Tests to Assess Students' Physical Fitness at Ho Chi Minh City University of Technology and Education (Viet Nam). International Journal of Human Movement and Sports Sciences, 9(5), 981 - 992. DOI: 10.13189/saj.2021.090520.

Copyright $\bigcirc 2021$ by authors, all rights reserved. Authors agree that this article remains permanently open access under the terms of the Creative Commons Attribution License 4.0 International License

\begin{abstract}
The purpose of this study is to select tests to assess physical fitness for students at Ho Chi Minh City University of Technical and Education (HCMC UTE). Through reference to scientific works that have been published in the country as well as abroad, the topic has synthesized 53 tests. On the basis of tests following the selection principles, the topic has omitted complicated and less common exercises, leaving 41 tests to include in the expert interview step. Proceeding a survey of 20 experts, lecturers of physical education and 600 students of Ho Chi Minh City University of Technology and Education, finally, the study selected 15 tests including: 03 morphological tests [Standing height $(\mathrm{cm})$, Weight $(\mathrm{kg}), \mathrm{BMI}] ; 08$ fitness tests [Lying on your back with sit-ups/30s (times), Standing flexible with your body flexed $(\mathrm{cm})$, Force of squeezing your dominant hand (KG), Jumping in place $(\mathrm{cm})$, Long jump $(\mathrm{cm})$, Shuttle running $4 \times 10 \mathrm{~m}(\mathrm{~s})$, Running $30 \mathrm{~m} \quad(\mathrm{~s}), \quad$ Running $\quad 800 \mathrm{~m} / 1500 \mathrm{~m}(\mathrm{~s}) ; 02$ physiological tests [Vital capacity (1), Cardiac function (Hw)]; ); 02 psychological tests [Test Tapping (e), LanDolt Open Loop (bit/s)]. These tests have met the conditions such as convention, as well as ensure reliability and informability to be included in the physical assessment test of students of Ho Chi Minh City University of Technology and Education. The research results will be a useful basis for adjusting the content and curricula, contributing to improving the physical quality of graduates, meeting the labor requirements of the society.
\end{abstract}

Keywords Assessment, Classification, Students, Physical, Technology and Education, Test

\section{Introduction}

Countries strive to achieve the best levels of life for their people, so it is noted that they are making efforts and devoting capabilities and wealth in order to build a sophisticated civilized society [10]. In the trend of integration and development, it is necessary to train human resources to meet the indispensable requirements of society. Physical education is one aspect of comprehensive education, training the young generation with solid professional capacity, pure moral qualities, healthy manners, good health in order to improve the quality of life, achieve the goal is rich people, strong country, democracy, justice and civilization [2].

Physical education is one of the important subjects in the general training program with the role of creating a class of people who not only have new knowledge, ability, and political qualities but also have abundant health to meet the requirements professional demand of the society. The study of Nedal Ahmad Alghafary (Jordan) has recommended that performing a thorough revision of the sport and health for all curriculums in order to integrate the 21 st century skills [11]. 
With a scale of more than 20,000 learners in different systems, the health assessment of learners has not been carried out regularly and periodically according to the regulations of the Ministry of Education and Training. Ho Chi Minh City University of Technology and Education (HCMC UTE) does not currently have routine tests to assess students' physical fitness. Therefore, this study aims to select tests to assess physical fitness for HCMC UTE students. Research results will be the basis for monitoring the physical quality of input and output to adjust and change the content of physical education to suit students and the requirements of each specific profession. Thereby, it contributes to the training of physically strong human resources.

\section{Materials and Methods}

\subsection{Research Object}

Objects of the study: The staff and lecturers of the Center of National Defense and Physical Education (20 people) and 600 male and female students with normal health, participating in physical education in non-specialized fields of HCMC UTE.

Scope of the study: Tests to assess students' physical fitness.

\subsection{Proceed}

The study was carried out from January to September 2019 to October 2020 at HCMC UTE.

\subsection{Measuring Tool}

Common methods used in the process of carrying out research tasks include: Synthesis and methodological analysis of related documents; Sociological Investigation; Pedagogical examination; Check psycho-physiological function; Statistics and calculations [3].

During the implementation of the project, we analyzed and synthesized relevant sources, as well as inherited the achievements of the research works of previous scientists. The topic also collected data, information, and survey subjects in both qualitative and quantitative aspects of the overall aspects of the physical examination, assessment and classification of students.

\section{Overall Study Design}

The study was conducted according to the following steps:

\section{(1) Design of questionnaire}

The topic has designed 2 questionnaires to simultaneously interview two subjects, students and experts of physical education about students at HCM UTE's physical examination, assessment and classification. Two questionnaires based on Likert scale 5 levels: Totally agree (5 marks); Agree (4 marks); Normal (3 marks); Disagree (2 marks); Totally disagree (1 mark). In which, the distance value $=$ (maximun minimun $) / \mathrm{n}=(5-1) / 5=0.8$.

The evaluation of the mean values will be divided into ranges: 1.00 - 1.80: Totally disagree; $1.81-2.60$ : Disagree; 2.61 - 3.4: Normal: 3.41 - 4.2: Agree: 4.21 - 5.00: Totally agree.

\section{(2) Selection of evaluation tests}

This step was conducted as follows:

(a) Synthesize and systematize the physical assessment tests of students that have been used by domestic and foreign authors

(b) Simplify less common tests

(c) Interview by questionnaire to get expert opinion (lecturers, coaches and other professionals who have been doing the work of guiding, mentoring, teaching and training PE and sport at HCMC UTE) to select tests for assessing students' physical fitness in an objective and feasible manner.

After surveying the variables using the Likert scale - 5 levels, the thesis in turn analyzes and evaluates the similarities between students and lectures by conducting hypotheses about the average value of 2 independent samples (Independent Samples T-Test).

In Independent-samples T-test, we need to rely on the test of the equality of the two general variances (Levene's test). The variance describes the uniformity or unevenness (dispersion) of observed data.

- If value Sig. in Levene's test (F-test) $<0.05$, the variance of the 2 different integers uses t-test results in Equal variances not assumed.

- If Sig. $\geq 0.05$, the variance of the 2 different integers is the same, then use the test results in Equal variances assumed.

- If Sig. of t-test $\leq \alpha$ (significance level), there is a significant difference in the average of the two integers and vice versa.

At the same time, the study also used SPSS software version 22.0 to process the collected data (through indicators such as mean, standard deviation, percentage, Spirimen hierarchical correlation coefficient, Chi-squared index, t-student test, Wilcoxon test ...) to ensure the reliability and persuasiveness of the research results.

(d) Check the reliability and informability of the selected tests

Note, the selected tests must adhere to the following basic principles: (a) Ensure reliability, informability, feasibility, low cost, ease of deployment; (b) Simple and easy to implement, suitable to the current conditions of 
metrology equipment of HCMC UTE; (c) These tests must meet the requirements of a comprehensive physical assessment of HCMC UTE students and can be compared with students of other universities throughout Vietnam.

In addition, this study also conventionally selects only the physical assessment tests of students with the rate of $\geq 80 \%$ agreeing through 2 interviews (removing the tests with the approval rate $<80 \%$ ). There must be consistency (no significant difference) between the two interviews (Sig.> 0.05). This result was obtained by conducting Wilcoxon rank test (Wilcoxon signed rank test) and Correlation coefficient (Pearson). In terms of properties: $-1<\mathrm{r}<1$; If $\mathrm{r}=0$ the two characteristics are independent; If $r>0$ between two characteristics there is a positive correlation (covariate); If $\mathrm{r}<0$ between two features there is a negative correlation.

Reliability of the tests: the topic has conducted to determine the reliability of the tests through the retest method (also known as repeated testing). The determination of the reliability coefficient between the results of 2 times of testing was performed 1 week apart at the same time of day, with the same conditions and subjects ( 30 male students and 30 female students). The tests are reliable if $r \geq 0.8$.

Informability of tests: The informability of the tests is shown by the correlation coefficient between the results of the tests and the learning results of the subject of General Education1 (the average score of the course). This is a basic course with the characteristics of equipping students with background physical strength, having all the characteristics of the motor aspects as in the selected tests. The tests are informative if $r \geq 0.6$.

The results identified 15 tests on morphological, physical, psychological and physiological functions (Reliability - $\mathrm{rtt} \geq 0.8$ and Informability - $\mathrm{rtc} \geq 0.6$ ). This is the basis to ensure the continuation of the physical examination and assessment of the students of HCMC UTE.

\section{Result and Discussion}

\subsection{Select Tests to Assess Students' Physical Fitness in Accordance with the Practical Conditions of HCMC UTE}

a. Interview experts, assess the role and status of physical fitness and determine the tests to assess students' physical fitness in accordance with the practical conditions of HCMC UTE

The interviewees were $20 \mathrm{PE}$ lecturers with degrees including: 01 Doctorate (accounting for 5\%); 17 Master (accounting for 85\%); 02 Bachelors (10\%) and seniority: $<3$ years ( $5 \%$ rate); $3-5$ years (reaching $20 \%$ ); $6-10$ years $(50 \%$ rate) $>>10$ years $(25 \%)$. With the form of indirect interview 2 times by questionnaire ( 2 weeks apart each time).

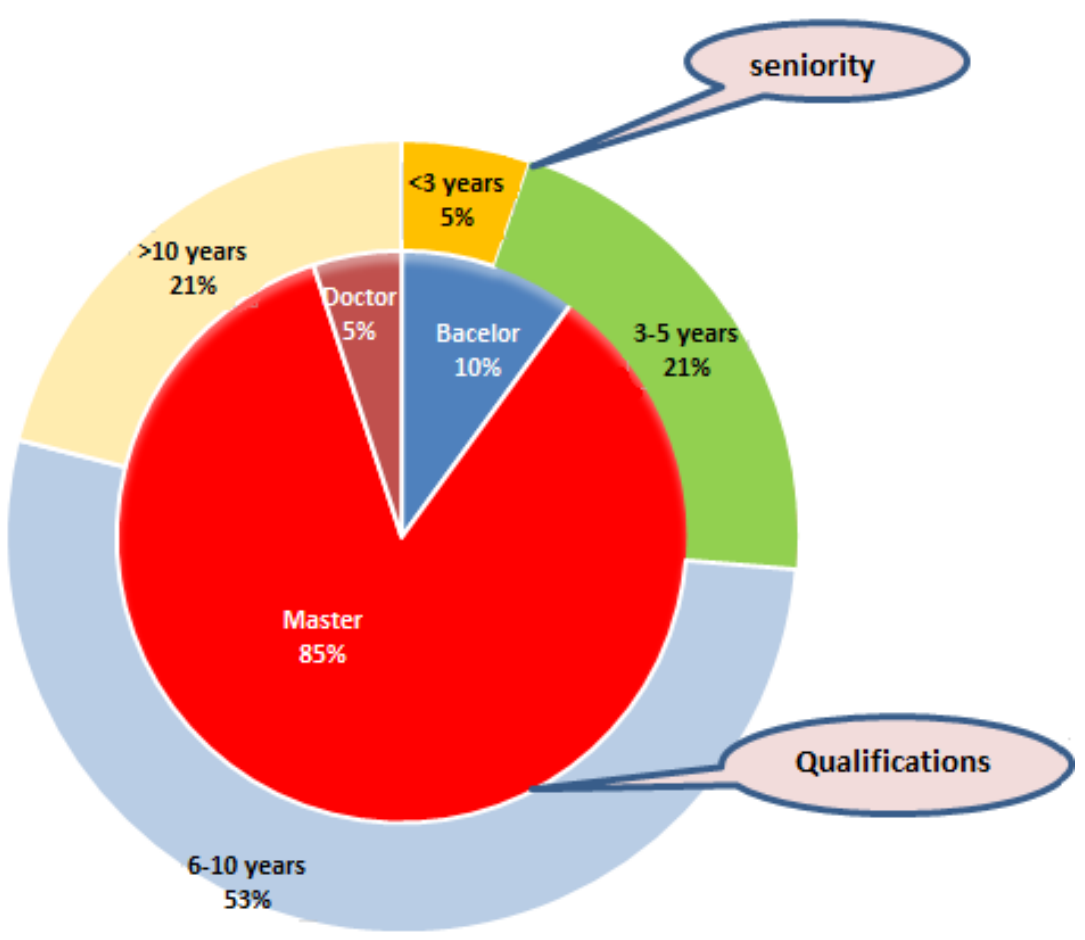

Figure 1. Qualifications and seniority of interviewees 
In order to ensure objectivity in the selection of evaluation criterion, the topic interviewed experts who are officials and lecturers of physical education (organic and visiting) at Ho Chi Minh City University of Technical Education about the necessity of select, test, and develop standards for physical assessment and classification of students there. The total number of interview questionnaires was given out 20 , the total number of questionnaires collected was 20. Experts answered each content recorded in the interview form by ticking (x) in the corresponding box. The specific results are as follows:

\section{On the role of physical fitness for students}

The survey shows that experts highly appreciate the role of physical activity in students (total score on Likert scale is $93 / 100$ ). The rating average is $4.65 / 5$, in the Very Important range (Table 1).

Compare the evaluation opinions between two subjects, lecturers and students, through the mean value and the t-student index. Research results in Table 2 and Figure 2 show that the role of physical education is highly appreciated by both lecturers and students. The corresponding mean $(\bar{X})$ between lecturers and students is 4.70 and 4.75 (equivalent to the Very Important scale).

Table 1. Summary of interview results of lecturers on physical examination and assessment of students $(n=20)$

\begin{tabular}{|c|c|c|c|c|c|c|c|c|}
\hline No & \multicolumn{2}{|c|}{ Content } & $\begin{array}{l}\text { The level of } \\
\text { evaluation }\end{array}$ & $\begin{array}{c}\text { Frequency } \\
\text { of comments }\end{array}$ & $\%$ & $\sum$ points $/ 100$ & $\bar{x}$ & $\pm \mathrm{S}$ \\
\hline \multirow{2}{*}{1} & \multirow{2}{*}{\multicolumn{2}{|c|}{$\begin{array}{l}\text { The role of physical fitness } \\
\text { towards students }\end{array}$}} & Important & 7 & 35 & \multirow{2}{*}{93} & \multirow{2}{*}{4.70} & \multirow{2}{*}{0.47} \\
\hline & & & Very important & 13 & 65 & & & \\
\hline \multirow{4}{*}{2} & \multirow{4}{*}{\multicolumn{2}{|c|}{ Student's physical status }} & $\begin{array}{c}\text { Comprehensive } \\
\text { development }\end{array}$ & 2 & 10 & \multirow{4}{*}{53} & \multirow{4}{*}{2.65} & \multirow{4}{*}{0.81} \\
\hline & & & Well development & 5 & 25 & & & \\
\hline & & & Normal development & 11 & 55 & & & \\
\hline & & & Thể chất yếu & 2 & 10 & & & \\
\hline \multirow{4}{*}{3} & \multirow{4}{*}{\multicolumn{2}{|c|}{$\begin{array}{l}\text { Assess and classify students' physical } \\
\text { fitness every year according to the spirit } \\
\text { of Decision No. 53/2008/QĐ-BGDĐT }\end{array}$}} & Unnecessary & 1 & 5 & \multirow{4}{*}{81} & \multirow{4}{*}{4.05} & \multirow{4}{*}{0.88} \\
\hline & & & Normal & 4 & 20 & & & \\
\hline & & & Necessary & 8 & 40 & & & \\
\hline & & & Very necessary & 7 & 35 & & & \\
\hline \multirow{12}{*}{4} & \multirow{12}{*}{$\begin{array}{l}\text { Evaluation } \\
\text { aspects }\end{array}$} & \multirow{3}{*}{ Morphology } & Normal & 3 & 15 & \multirow{3}{*}{87} & \multirow{3}{*}{4.35} & \multirow{3}{*}{0.74} \\
\hline & & & Agree & 7 & 35 & & & \\
\hline & & & Totally agree & 10 & 50 & & & \\
\hline & & \multirow{3}{*}{ Physical strength } & Normal & 1 & 5 & \multirow{3}{*}{93} & \multirow{3}{*}{4.65} & \multirow{3}{*}{0.58} \\
\hline & & & Agree & 5 & 25 & & & \\
\hline & & & Totally agree & 14 & 70 & & & \\
\hline & & \multirow{3}{*}{ Physiology } & Normal & 1 & 5 & \multirow{3}{*}{87} & \multirow{3}{*}{4.35} & \multirow{3}{*}{0.58} \\
\hline & & & Agree & 11 & 55 & & & \\
\hline & & & Totally agree & 8 & 40 & & & \\
\hline & & & Normal & 3 & 15 & \multirow{3}{*}{80} & \multirow{3}{*}{4.00} & \multirow{3}{*}{0.56} \\
\hline & & Psychology & Agree & 14 & 70 & & & \\
\hline & & & Totally agree & 3 & 15 & & & \\
\hline
\end{tabular}


Table 2. Comparison of the assessment of lecturers and students on the role, physical status, physical examination and assessment for students of HCMC UTE

\begin{tabular}{|c|c|c|c|c|c|c|c|c|c|c|}
\hline \multirow[t]{2}{*}{ No } & \multirow{2}{*}{\multicolumn{2}{|c|}{ Criterion }} & \multirow[t]{2}{*}{ Objects } & \multirow[t]{2}{*}{$\mathbf{N}$} & \multicolumn{2}{|c|}{$\begin{array}{c}\text { Levene's Test for } \\
\text { Equality } \\
\text { of Variances }\end{array}$} & \multirow[t]{2}{*}{$\begin{array}{c}\bar{x} \\
\text { (Mean) }\end{array}$} & \multirow{2}{*}{$\begin{array}{c} \pm \text { SD } \\
\text { (Std. } \\
\text { Deviation) }\end{array}$} & \multirow[t]{2}{*}{ t } & \multirow[t]{2}{*}{$\begin{array}{c}\text { Sig. } \\
\text { (2- tailed) }\end{array}$} \\
\hline & & & & & $\mathrm{F}$ & Sig. & & & & \\
\hline \multirow{2}{*}{1} & \multirow{2}{*}{\multicolumn{2}{|c|}{$\begin{array}{l}\text { The role of physical fitness } \\
\text { towards students }\end{array}$}} & Lecturers & 20 & \multirow{2}{*}{.47} & \multirow{2}{*}{0.49} & 4.70 & .47 & \multirow{2}{*}{-0.34} & \multirow{2}{*}{0.73} \\
\hline & & & Students & 600 & & & 4.75 & .44 & & \\
\hline \multirow{2}{*}{2} & \multirow{2}{*}{\multicolumn{2}{|c|}{ Student's physical status }} & Lecturers & 20 & \multirow{2}{*}{1.12} & \multirow{2}{*}{0.29} & 2.65 & .81 & \multirow{2}{*}{-1.60} & \multirow{2}{*}{0.11} \\
\hline & & & Students & 600 & & & 3.05 & .75 & & \\
\hline \multirow[b]{2}{*}{3} & \multirow{2}{*}{\multicolumn{2}{|c|}{$\begin{array}{c}\text { Assess and classify students' } \\
\text { physical fitness every year } \\
\text { according to the spirit of } \\
\text { Decision No. } \\
\text { 53/2008/QĐ-BGDĐT }\end{array}$}} & Lecturers & 20 & \multirow[b]{2}{*}{2.44} & \multirow[b]{2}{*}{0.12} & 4.05 & .88 & \multirow[b]{2}{*}{0.20} & \multirow[b]{2}{*}{0.84} \\
\hline & & & Students & 600 & & & 4.00 & .64 & & \\
\hline \multirow{8}{*}{4} & \multirow{8}{*}{$\begin{array}{l}\text { Evaluation } \\
\text { aspects }\end{array}$} & \multirow{2}{*}{ Morphology } & Lecturers & 20 & \multirow{2}{*}{1.49} & \multirow{2}{*}{0.22} & 4.35 & .74 & \multirow{2}{*}{-0.23} & \multirow{2}{*}{0.81} \\
\hline & & & Students & 600 & & & 4.40 & .59 & & \\
\hline & & \multirow{2}{*}{$\begin{array}{l}\text { Physical } \\
\text { strength }\end{array}$} & Lecturers & 20 & \multirow{2}{*}{1.87} & & 4.65 & .58 & & \\
\hline & & & Students & 600 & & 0.17 & 4.75 & .44 & -0.60 & 0.54 \\
\hline & & & Lecturers & 20 & & & 4.35 & .58 & & \\
\hline & & Physiology & Students & 600 & 0.45 & 0.50 & 4.40 & .50 & -0.28 & 0.77 \\
\hline & & & Lecturers & 20 & & & 4.00 & .56 & & \\
\hline & & Psychology & Students & 600 & 0.94 & 0.76 & 3.85 & .60 & 0.94 & 0.37 \\
\hline
\end{tabular}

\section{$\bar{x} \quad$ uLecturers $\quad$ Students}

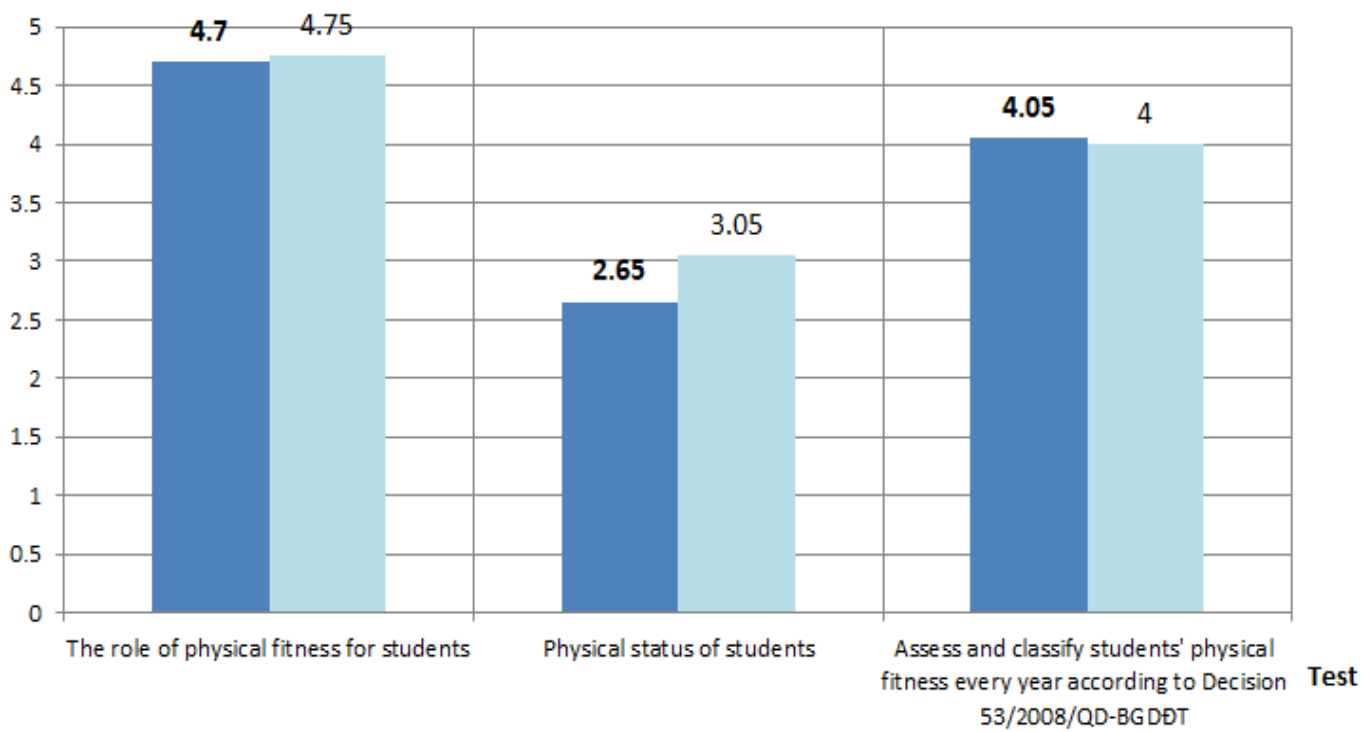

Figure 2. Comparison of assessment of physical work at HCMC UTE 


\section{About student's physical condition}

The survey recorded that $55 \%$ of experts' opinions were rated as normal, (the total score on the Likert scale was $53 / 100$ ). The assessment average score is $2.65 / 5$, within the range of Normal. It shows that the physical condition of the students at the University of Technical Education in Ho Chi Minh City, as assessed by experts, is not very good and needs to be improved.

Compare the evaluation opinions between two subjects, lecturers and students, through the mean value and the t-student index. The research results in Table 2 and Figure 2 show that the physical condition of students is not very good. The corresponding mean $(\bar{X})$ between lecturers and students is 2.65 and 3.05 (within the Normal scale range).

Obviously, there is a high consensus between lecturers and students when they do not appreciate the physical condition of students at HCMC UTE. Thereby, it is necessary to pay attention to take measures to improve the learners' physical condition.

Regarding the assessment and classification of students' physical fitness on an annual basis in the spirit of Decision No. 53/2008/QD-BGDÐT

The Ministry of Education and Training of Vietnam has stipulated: Educational institutions are responsible for preparing facilities, staff, and lecturers to ensure that the assessment of student fitness is convenient, safe and effective. At the same time, there must be a plan to test, evaluate and grade students' physical fitness annually, arrange a reasonable time to organize the test, record and keep records of the results of the assessment and classification of physical fitness of each student, summarizing and reporting to the direct management agency annually [2].

The actual survey results show that $75 \%$ of experts say that it is necessary and necessary to conduct an annual assessment and classification of students' fitness in the spirit of Decision No. 53/2008/QD-BGDĐT (total score on Likert scale is $81 / 100)$. The assessment average score is $4.05 / 5$, in the Necessary range (Table 1 ).

Compare the evaluation opinions between the two subjects of lecturers and students through the value and t-student index. Research results in table 2 and figure 2 show that both teachers and students believe that conducting annual assessment and classification of students' fitness in the spirit of Decision No. $53 / 2008 /$ QD-BGDĐT is Necessary. The mean value $(\bar{X})$ of the respective assessment between lectures and students is 4.05 and 4.0 .

Thereby, it shows that there is a similarity between lecturers and students when they highly appreciate the need to conduct annual physical examination and assessment of students at HCMC UTE.

\section{In terms of evaluation}

In addition to enhancing the resistance and adaptive capacity of the human body, physical education and sport play a great role in improving overall health. Comprehensive health must have full development in terms of: morphology, physical strength (speed, strength, endurance, dexterity, coordination of movement), psychology and physiology. These factors can only be achieved through regular exercise. Once people have comprehensive health, their physical capacity will be improved [4]. The survey specifically noted the following:

- Morphological aspect: $85 \%$ of experts' opinions expressed their agreement when assessing at the level of Agree and Totally Agree, (total score according to Likert scale is $87 / 100$ ). The average rating is $4.35 / 5$, in the Totally Agree range (Table 1).

The results of comparing opinions between two subjects, lecturers and students through the mean and student t-index presented in table 3 and figure 2, show that both lecturers and students agree highly when choosing morphology tests to assess student's physicality. The corresponding mean $(\bar{X})$ between lecturers and students is 4.35 and 4.4 (both within the Totally Agree scale).

Thus, there is a high similarity between lecturers and students when choosing to conduct physical examination and assessment of students in terms of morphology.

- Physical aspect: 95\% of experts' opinions expressed their approval when assessed at the level of Agree and Totally agree, (total score according to Likert scale is $93 / 100$ ). The rating average score is $4.65 / 5$, in the range of Totally Agree (Table 1).

Through comparing the evaluation opinions between two subjects, lecturers and students through the value and t-student index presented in table 2 and figure 2. It shows that both lecturers and students agree highly when choosing fitness tests used to assess students' physical fitness. The corresponding mean $(\bar{X})$ between lecturers and students is 4.65 and 4.75 (both within the Totally Agree scale).

Thus, between lecturers and students, there is a high similarity when choosing to test and assess students' physical fitness in terms of fitness.

- Physiological side: $95 \%$ of the experts' opinions expressed their agreement when assessing at the level of Agree and Totally agree, (total score according to Likert scale is $87 / 100$ ). The average rating is $4.35 / 5$, in the Totally Agree range (Table 1). 
Table 3. Tests are compiled from domestic and foreign documents

\begin{tabular}{|c|c|c|c|}
\hline Morphological test group & Fitness test group & Physiological test group & Psychological test group \\
\hline $\begin{array}{l}\text { 1. Standing height }(\mathrm{cm}) \\
\text { 2. Sitting height }(\mathrm{cm}) \\
\text { 3. Weight }(\mathrm{kg}) \\
\text { 4. BMI } \\
\text { 5. Quetelet index } \\
\text { 6. Bust average }(\mathrm{cm}) \\
\text { 7. Waist circumference }(\mathrm{cm}) \\
\text { 8. Butt circumference }(\mathrm{cm}) \\
\text { 9. Thigh circumference }(\mathrm{cm}) \\
\text { 10. Arm circumference }(\mathrm{cm}) \\
\text { 11. Body volume }(\mathrm{dm} 3) \\
\text { 12. Body Mass Ratio }\end{array}$ & $\begin{array}{l}\text { 13. Vertical/horizontal pressing }(\mathrm{cm}) \\
\text { 14. Standing flexible bending body } \\
(\mathrm{cm}) \\
\text { 15. Jump away in place (cm) } \\
\text { 16. Cross jump (d) } \\
\text { 17. Lie on your back with sit-ups } / 30 \mathrm{~s} \\
\text { (times) } \\
\text { 18. Lie on your stomach with your } \\
\text { back bent } / 30 \mathrm{~s} \text { (times) } \\
\text { 19. Lie on your stomach doing } \\
\text { push-ups (times) } \\
\text { 20. Hand grip force }(\mathrm{KG}) \\
\text { 21. Reverse hand grip force }(\mathrm{KG}) \\
\text { 22. Back force }(\mathrm{KG}) \\
\text { 23. Foot force }(\mathrm{KG}) \\
\text { 24. Pull up bar (times) } \\
\text { 25. Swing arm pull up bar (s) } \\
\text { 26. Jump } 3 \text { steps without momentum } \\
\text { (cm) } \\
\text { 27. Long jump (cm) } \\
\text { 28. Shuttle Running } 4 x 10 \mathrm{~m}(\mathrm{~s}) \\
\text { 29. Running } 30 \mathrm{~m}(\mathrm{~s}) \\
\text { 30. Running } 60 \mathrm{~m}(\mathrm{~s}) \\
\text { 31. Running } 100 \mathrm{~m}(\mathrm{~s}) \\
\text { 32. Running } 200 \mathrm{~m}(\mathrm{~s}) \\
\text { 33. Running } 400 \mathrm{~m}(\mathrm{~s}) \\
\text { 34. Running } 5 \mathrm{minutes} \text { depending on } \\
\text { strength (m) } \\
\text { 35. Running } 800 / 1500 \mathrm{~m}(\mathrm{~s}) \\
\text { 36. Running } 5000 \mathrm{~m}(\mathrm{~s})\end{array}$ & $\begin{array}{l}\text { 37. Pulse (times/minute) } \\
\text { 38. Blood pressure (mmHg) } \\
\text { 39. Cardiac function (Hw) } \\
\text { 40. Vital capacity (l) } \\
\text { 41. Breathing time (s) } \\
\text { 42. Step-Test Haward } \\
\text { 43. Margaria test } \\
\text { (Margaria-Kalamen test) } \\
\text { 44. Test Cooper (km) } \\
\text { 45. VO2 max } \\
\text { 46. Test PWC } 170 \text { (Physical } \\
\text { Working Capacity) }\end{array}$ & $\begin{array}{l}\text { 47. Auditory-visual-motor } \\
\text { reflex test (ms) } \\
\text { 48. Test Tapping (p) } \\
\text { 49. LanDolt open loop (bit/s) } \\
\text { 50. Test to assess the ability to } \\
\text { distribute attention } \\
\text { 51. Test to assess creativity } \\
\text { 52. Test of flexibility } \\
\text { 53. Test to assess the ability to } \\
\text { calm down }\end{array}$ \\
\hline
\end{tabular}

Compare the evaluation opinions between two subjects, lecturers and students through the mean and t-student index presented in table 2 and figure 2 recorded, both lecturers and students agree highly when choosing physical tests to assess students' physical fitness. The corresponding mean $(\bar{X})$ between lecturers and students is 4.35 and 4.40 (both within the Totally Agree scale).

Thus, there is a high degree of similarity between lecturers and students when choosing to test and evaluate students' physical fitness in terms of physiology.

- Psychological side: $85 \%$ of experts' opinions expressed their approval when assessing at the level of Agree and Totally Agree, (total score according to Likert scale is $80 / 100$ ). The average rating is $4.0 / 5$, in the Agree range.

When comparing the evaluation opinions between two subjects, lecturers and students through the mean and t-student index presented in table 2 and figure 2. It was found that both lecturers and students agreed to choose psychological tests to assess students' physical fitness. The corresponding mean $(\bar{x})$ between lecturers and students is 4.0 and 3.85 (both within the Totally Agree scale).

Thus, there is a similarity between lecturers and students when choosing to test and evaluate students' physical fitness in terms of psychology.

The synthesis of selected opinions of teachers (experts in physical education) and students (learners of physical education) is the basis to ensure that the topic continues to conduct survey steps to select tests used to evaluate and classify students' fitness.

\section{b. Selection of evaluation tests}

In order to select the indicator to assess the physical development level of HCMC UTE students, the project has followed the following steps:

- Step 1. Synthesize and systematize the physical assessment tests of students that have been used by domestic and foreign authors.

- Step 2. Shorten the less popular tests.

- Step 3. Interview by questionnaire to get expert opinion (lecturers, coaches and professionals who have been doing the work of guiding, mentoring, teaching PE, training sports at HCMC UTE) to select tests to assess students' physical fitness in an objective and feasible manner.

- Step 4. Check the reliability and informability of the selected tests.

Synthesize and systematize student physical assessment tests that have been used by authors in Vietnam and abroad [8] [9]

Through reference to scientific works published in the country as well as abroad, [1] [5] [6] [7] the topic has synthesized 53 tests (12 morphological tests; 24 physical 
tests; 10 physiological tests and 7 psychological tests) to include in the selection of students' fitness assessment and classification as follows:

\section{c. Ignore the less popular tests}

On the basis of synthetic tests and following selection principles, the study has omitted complicated, less popular or almost unused tests in assessing student fitness in universities. The remaining results of 41 tests to include in the next step of interviewing experts:

- Morphological test group [1. Standing height $(\mathrm{cm})$; 2. Sitting height (cm); 3. Weight (kg); 4. BMI index; 5 . Quetelet Index; 6. Average bust $(\mathrm{cm})$; 7. Thigh circumference $(\mathrm{cm}) ; 8$. Arm circumference $(\mathrm{cm})$

- Fitness test group [9. Vertical/horizontal $(\mathrm{cm}) ; 10$. Standing flexible bending body $(\mathrm{cm}) ; 11$. Displacement in place $(\mathrm{cm}) ; 12$. High bounce in place (cm); 13. Cross jump (đ); 14. Lie on your back with sit-ups/30s (times); 15. Lie on your stomach with your back bent/30s (times); 16. Lie on your stomach doing push-ups (times); 17. Hand squeeze force (KG); 18. Reverse hand squeeze force (KG); 19. Back force (KG); 20. Foot force (KG); 21. Pull up bar (times); 22. Running the shuttle $4 \times 10 \mathrm{~m}(\mathrm{~s}) ; 23$. Running $30 \mathrm{~m}(\mathrm{~s})$; 24. Running $60 \mathrm{~m}(\mathrm{~s}) ; 25$. Running $100 \mathrm{~m}(\mathrm{~s}) ; 26$. Running 200m(s); 27. Running 400m(s); 28. Running for 5 minutes depending on strength (m);29. Running $800 / 1500 \mathrm{~m}(\mathrm{~s})]$

- Physiological test group [31. Pulse (times/minute); 32. Blood pressure $(\mathrm{mmHg}) ; 33$. Cardiac function (Hw); 34. Vital capacity (l); 35. Breathing time (s); 36. Step-Test Haward; 37. Test Cooper (km)

- Psychological test group [38. Test of auditory-optical reflexes (ms); 39. Test Tapping (đ); 40. LanDolt open loop bit/s; 41. Test to assess the ability to distribute attention; 42. Test assesses creativity.
About the selection of tests for assessment and classification students' physical fitness

After omitting from 54 tests remaining 41 tests, the study continued to interview PE lectures who have been teaching PE at HCMC UTE to select tests used to assess students' physical fitness.

The selected tests must adhere to the following basic principles:

- Ensure reliability, notification, feasibility, low cost, easy to deploy.

- Simple and easy to implement, suitable to the current conditions, machinery for measurement at HCMC UTE.

- These tests must ensure the comprehensive physical assessment of students and can be compared with students of other universities nationwide.

In addition, the topic also conventions to choose only the physical assessment tests of students with the rate of $\geq$ $80 \%$ of the positive opinions through 2 interviews (removing the tests with the approval rate $<80 \%$ ). At the same time, there must be consistency (no significant difference) between the two interviews (Sig. > 0.05).

Each test in the questionnaire has 5 levels of choice according to the Likert scale to answer: Totally agree (5 marks); Agree (4 marks); Normal (3 marks); Disagree (2 marks); Totally disagree (1 marks).

After conducting the survey, it was found that the number of votes sent and received in the first and second interviews was 20; the specific results in the tables were reflected as follows:

a. Morphological tests: there are 3/8 tests [Standing height $(\mathrm{cm})$; Weight $(\mathrm{kg})$; BMI] with $\geq 80 \%$ approval. Simultaneously conducting Wilcoxon rank test (Wilcoxon signed rank test), it was noted that all $8 / 8$ morphometric tests for selection interviews have $\mathrm{Sig}>0.05$, proving that there is no statistically significant difference in opinions between the two interviews (Table 4).

Table 4. Results of expert consultation to select morphological tests (by Wilcoxon method of 2 interviews)

\begin{tabular}{|c|c|c|c|c|c|c|c|}
\hline \multirow{2}{*}{ № } & \multirow{2}{*}{ Test } & \multicolumn{2}{|c|}{$1 \mathrm{st}(\mathrm{n}=20)$} & \multicolumn{2}{|c|}{ 2nd $(n=20)$} & \multicolumn{2}{|c|}{ Test Statistics ${ }^{\mathrm{a}}$} \\
\hline & & $\sum$ marks & $\%$ & $\sum$ marks & $\%$ & $\mathrm{Z}$ & Asymp. Sig. (2-tailed) \\
\hline 1 & Standing height $(\mathrm{cm})$ & 89 & 89 & 93 & 93 & $-1.414^{\mathrm{b}}$ & .157 \\
\hline 2 & Sitting height $(\mathrm{cm})$ & 44 & 44 & 43 & 43 & $-.302^{\mathrm{c}}$ & .763 \\
\hline 3 & Weight (kg) & 86 & 86 & 85 & 85 & $-.447^{\mathrm{c}}$ & .655 \\
\hline 4 & BMI index & 83 & 83 & 81 & 81 & $-.816^{\mathrm{c}}$ & .414 \\
\hline 5 & Quetelet Index & 49 & 49 & 50 & 50 & $-.447^{\mathrm{b}}$ & .655 \\
\hline 6 & Average bust $(\mathrm{cm})$ & 41 & 41 & 43 & 43 & $-.816^{\mathrm{b}}$ & .414 \\
\hline 7 & Thigh circumference $(\mathrm{cm})$ & 45 & 45 & 43 & 43 & $-1.000^{c}$ & .317 \\
\hline 8 & Arm circumference $(\mathrm{cm})$ & 40 & 40 & 40 & 40 & $.000^{\mathrm{d}}$ & 1.000 \\
\hline
\end{tabular}


Fitness tests: there are 7/23 tests [Standing flexible and bending body $(\mathrm{cm})$; Jump away in place $(\mathrm{cm})$; Lie on your back with sit-ups/30s (times); Dominant grip force (KG); Running the shuttle $4 \times 10 \mathrm{~m}(\mathrm{~s})$; Running $30 \mathrm{~m}(\mathrm{~s})$; Running average distance $800 / 1500 \mathrm{~m}(\mathrm{~s})]$ has $\geq 80 \%$ approval rate. Along with conducting the Wilcoxon rank test (Wilcoxon signed rank test), it was also noted that all 23/23 fitness tests selected for the interview had $\mathrm{Sig}>0.05$. This shows that there is no statistically significant difference between the two interviews (Table 5).

Physiological tests: there are 2/8 tests [Heart function (Hw); Vital capacity (1)] has a rate of $\geq 80 \%$ of the opinions. Conducted Wilcoxon rank test (Wilcoxon signed rank test), also noted: all $8 / 8$ physiological tests selected for interviews have $\mathrm{Sig}>0.05$ values. This shows that there is no statistically significant difference between the two opinions of experts (Table 6).

Table 5. Results of consultation with experts to select fitness tests (by Wilcoxon method of 2 interviews)

\begin{tabular}{|c|c|c|c|c|c|c|c|}
\hline \multirow[b]{2}{*}{ № } & \multirow[b]{2}{*}{ Test } & \multicolumn{2}{|c|}{$1 \mathrm{st}(\mathrm{n}=20)$} & \multicolumn{2}{|c|}{ 2nd $(\mathrm{n}=20)$} & \multicolumn{2}{|c|}{ Test Statistics $^{\mathrm{a}}$} \\
\hline & & $\sum$ marks & $\%$ & $\sum_{\text {marks }}$ & $\%$ & $\mathrm{Z}$ & $\begin{array}{l}\text { Asymp. Sig. } \\
\text { (2-tailed) }\end{array}$ \\
\hline 1 & Vertical/horizontal split (cm) & 44 & 44 & 42 & 42 & $-.632^{\mathrm{c}}$ & .527 \\
\hline 2 & Standing flexible bending body $(\mathrm{cm})$ & 86 & 86 & 85 & 85 & $-.237^{\mathrm{c}}$ & .813 \\
\hline 3 & Jump away in place $(\mathrm{cm})$ & 84 & 84 & 83 & 83 & $-.378^{\mathrm{c}}$ & .705 \\
\hline 4 & High bounce in place $(\mathrm{cm})$ & 42 & 42 & 41 & 41 & $-.333^{\mathrm{c}}$ & .739 \\
\hline 5 & Cross jump (d) & 37 & 37 & 39 & 39 & $-.816^{\mathrm{b}}$ & .414 \\
\hline 6 & Lie on your back with sit-ups/30s (time) & 86 & 86 & 84 & 84 & $-.707^{c}$ & .480 \\
\hline 7 & $\begin{array}{c}\text { Lie on your stomach with your back bent/30s } \\
\text { (times) }\end{array}$ & 37 & 37 & 37 & 37 & $.000^{\mathrm{d}}$ & 1.000 \\
\hline 8 & Lie face down push-ups (times) & 38 & 38 & 40 & 40 & $-.707^{\mathrm{b}}$ & .480 \\
\hline 9 & Hand grip force $(\mathrm{KG})$ & 84 & 84 & 85 & 85 & $-.333^{\mathrm{b}}$ & .739 \\
\hline 10 & Reverse hand grip force $(\mathrm{KG})$ & 44 & 44 & 42 & 42 & $-.707^{\mathrm{c}}$ & .480 \\
\hline 11 & Back Force (KG) & 39 & 39 & 38 & 38 & $-.302^{\mathrm{c}}$ & .763 \\
\hline 12 & Foot force $(\mathrm{KG})$ & 33 & 33 & 32 & 32 & $-.378^{\mathrm{c}}$ & .705 \\
\hline 13 & Pull up bar (times) & 49 & 49 & 47 & 47 & $-.577^{\mathrm{c}}$ & .564 \\
\hline 14 & Jump 3 steps without momentum $(\mathrm{cm})$ & 36 & 36 & 37 & 37 & $-.258^{\mathrm{b}}$ & .796 \\
\hline 15 & Long jump $(\mathrm{cm})$ & 83 & 83 & 85 & 85 & -1.000 & .317 \\
\hline 16 & Running the shuttle $4 \times 10 \mathrm{~m}(\mathrm{~s})$ & 83 & 83 & 81 & 81 & $-.577^{\mathrm{c}}$ & .564 \\
\hline 17 & Running $30 \mathrm{~m}(\mathrm{~s})$ & 83 & 83 & 85 & 85 & $-.587^{\mathrm{b}}$ & .557 \\
\hline 18 & Running $60 \mathrm{~m}(\mathrm{~s})$ & 36 & 36 & 34 & 34 & $-.540^{\mathrm{c}}$ & .589 \\
\hline 19 & Running $100 \mathrm{~m}(\mathrm{~s})$ & 36 & 36 & 34 & 34 & $-.577^{\mathrm{c}}$ & .564 \\
\hline 20 & Running $200 \mathrm{~m}(\mathrm{~s})$ & 32 & 32 & 34 & 34 & $-.707^{\mathrm{b}}$ & .480 \\
\hline 21 & Running $400 \mathrm{~m}(\mathrm{~s})$ & 35 & 35 & 37 & 37 & $-.707^{\mathrm{b}}$ & .480 \\
\hline 22 & $\begin{array}{l}\text { Running for } 5 \text { minutes depending on your } \\
\text { strength }(\mathrm{m})\end{array}$ & 51 & 51 & 46 & 46 & $-1.311^{\mathrm{c}}$ & .190 \\
\hline 23 & Running 800/1500m(s) & 84 & 84 & 85 & 85 & $-.378^{\mathrm{b}}$ & .705 \\
\hline 24 & Running $5000 \mathrm{~m}(\mathrm{~s})$ & 34 & 34 & 33 & 33 & $-.447^{\mathrm{c}}$ & .655 \\
\hline
\end{tabular}

Table 6. Results of consultation with experts to select physiological tests (by Wilcoxon method of 2 interviews)

\begin{tabular}{|c|c|c|c|c|c|c|c|}
\hline \multirow[b]{2}{*}{ № } & \multirow[b]{2}{*}{ Test } & \multicolumn{2}{|c|}{$1 \mathrm{st}(\mathrm{n}=20)$} & \multicolumn{2}{|c|}{ 2nd $(n=20)$} & \multicolumn{2}{|c|}{ Test Statistics ${ }^{\mathrm{a}}$} \\
\hline & & $\sum$ marks & $\%$ & $\sum$ marks & $\%$ & $\mathrm{Z}$ & $\begin{array}{l}\text { Asymp. Sig. } \\
\text { (2-tailed) }\end{array}$ \\
\hline 1 & Pulse (times/minute) & 40 & 40 & 36 & 36 & $-1.633^{c}$ & .102 \\
\hline 2 & Blood pressure $(\mathrm{mmHg})$ & 38 & 38 & 35 & 35 & $-1.134^{\mathrm{c}}$ & .257 \\
\hline 3 & Cardiac function (Hw) & 83 & 83 & 83 & 83 & $.000^{\mathrm{d}}$ & 1.000 \\
\hline 4 & Vital capacity (1) & 86 & 86 & 82 & 82 & $-1.414^{\mathrm{c}}$ & .157 \\
\hline 5 & Time without breathing (s) & 33 & 33 & 36 & 36 & $-.791^{\mathrm{b}}$ & .429 \\
\hline 6 & Step-Test Haward & 38 & 38 & 37 & 37 & -.378 & .705 \\
\hline 7 & $\begin{array}{c}\text { Test Margaria } \\
\text { (Margaria-Kalamen test) }\end{array}$ & 28 & 28 & 30 & 30 & $-.816^{\mathrm{b}}$ & .414 \\
\hline 8 & Test Cooper (km) & 34 & 34 & 33 & 33 & $-.447^{\mathrm{c}}$ & .655 \\
\hline
\end{tabular}


Table 7. Results of consultation with experts to select psychological tests (by Wilcoxon method of 2 interviews)

\begin{tabular}{|c|c|c|c|c|c|c|c|}
\hline \multirow[b]{2}{*}{ No } & \multirow[b]{2}{*}{ Test } & \multicolumn{2}{|c|}{1 st $(n=20)$} & \multicolumn{2}{|c|}{ 2nd $(n=20)$} & \multicolumn{2}{|c|}{ Test Statistics $^{\mathrm{a}}$} \\
\hline & & $\sum$ marks & $\%$ & $\sum_{\text {marks }}$ & $\%$ & $Z$ & $\begin{array}{c}\text { Asymp. Sig. } \\
\text { (2-tailed) }\end{array}$ \\
\hline 1 & Auditory-visual-motor reflex test (ms) & 36 & 36 & 35 & 35 & $-.378^{\mathrm{c}}$ & .705 \\
\hline 2 & Test Tapping (marks) & 80 & 80 & 81 & 81 & $-.577^{\mathrm{b}}$ & .564 \\
\hline 3 & LanDolt Open Loop (bit/s) & 82 & 82 & 82 & 82 & $.000^{\mathrm{d}}$ & 1.000 \\
\hline 4 & Test to assess the ability to distribute attention & 42 & 42 & 40 & 40 & $-.707^{\mathrm{c}}$ & .480 \\
\hline 5 & Test to assess creativity & 39 & 39 & 40 & 40 & $-.333^{\mathrm{b}}$ & .739 \\
\hline 6 & Flexibility test & 36 & 36 & 36 & 36 & $.000^{\mathrm{d}}$ & 1.000 \\
\hline 7 & Test to assess the ability to calm down & 39 & 39 & 34 & 34 & $-1.667^{\mathrm{c}}$ & .096 \\
\hline
\end{tabular}

Psychological tests: there are $2 / 7$ tests [Test Tapping (e); LanDolt open-loop] has $\geq 80 \%$ of the total votes. Along with Wilcoxon's rank test (Wilcoxon signed rank test), it is also noted that all $8 / 8$ psychological selection tests have $\operatorname{Sig}>0.05$, which shows the opinion between the two interviews of experts. There is no statistically significant difference (Table 7).

In summary, from 41 tests that were synthesized, through expert opinion, the topic has selected 15 tests that satisfy the conditions as convention, which are:

Table 8. The tests are summarized last to be included in assessment of students' physical fitness at the HCMC UTE

\begin{tabular}{|c|l|}
\hline Morphological tests & $\begin{array}{l}\text { (1) Standing height (cm) } \\
\text { (2) Weight (kg) } \\
\text { (3) BMI }\end{array}$ \\
\hline \multirow{5}{*}{ Fitness tests } & $\begin{array}{l}\text { (4) Lie on your back with sit-ups/30s } \\
\text { (times) } \\
\text { (5) Standing flexible bending body (cm) } \\
\text { (6) Hand grip force (KG) } \\
\text { (7) Jump away in place (cm) } \\
\text { (8) Long jump (cm) } \\
\text { (9) Shuttle Running 4x10m(s) } \\
\text { (10) Running 30m(s) } \\
\text { (11) Running 800m/1500m(s) }\end{array}$ \\
\hline Physiological tests & $\begin{array}{l}\text { (12) Vital capacity (l) } \\
\text { (13) Cardiac Function (Hw) }\end{array}$ \\
\hline Psychological tests & $\begin{array}{l}\text { (14) Test Tapping (d) } \\
\text { (15) LanDolt Open Loop (bit/s) }\end{array}$ \\
\hline
\end{tabular}

\section{Check reliability and informability of selection tests}

For the purpose of testing the feasibility of the selected tests, we determined the informability and reliability of the physical, physiological and psychological tests (the morphological tests alone have high stability so no need to retest). The specific results are as follows:

- Reliability of tests: the topic has conducted to determine the reliability of the tests through the retest method [repeat test, determine the reliability coefficient between the results of 2 times of testing (one week apart) at same time of day, same conditions and subjects; 30 male students and 30 female students).

- Informability of tests: The informability of the tests is shown by the correlation coefficient between the results of the tests and the learning results of the physical education module 1 (the average score of the course). This is a basic course with the characteristics of equipping students with background physical strength and it has all the features of the motor aspects as in the selected tests.

The results of determining the reliability and informability of the tests on research subjects are presented in Table 9 and 10.

Table 9. Tests for reliability and informability of tests on male students $(\mathrm{n}=30)$

\begin{tabular}{|c|l|c|c|}
\hline \multirow{2}{*}{ No } & \multicolumn{1}{|c|}{ Test } & \multicolumn{2}{|c|}{$\mathbf{R}$} \\
\cline { 3 - 4 } & & $\mathbf{r}_{\text {tt }}$ & $\mathbf{r}_{\text {tc }}$ \\
\hline 1 & (1) Standing height (cm) & 0.87 & 0.75 \\
\hline 2 & (2) Weight (kg) & 0.82 & 0.61 \\
\hline 3 & (3) BMI & 0.84 & 0.62 \\
\hline 4 & $\begin{array}{l}\text { (4) Lie on your back with sit-ups/30s } \\
\text { (times) }\end{array}$ & 0.85 & 0.76 \\
\hline 5 & $\begin{array}{l}\text { (5) Standing flexible bending body } \\
\text { (cm) }\end{array}$ & 0.89 & 0.70 \\
\hline 6 & (6) Hand grip force (KG) & 0.82 & 0.78 \\
\hline 7 & (7) Jump away in place (cm) & 0.91 & 0.85 \\
\hline 8 & (8) Long jump (cm) & 0.93 & 0.83 \\
\hline 9 & (9) Shuttle running 4x10m (s) & 0.88 & 0.70 \\
\hline 10 & (10) Running 30m (s) & 0.95 & 0.82 \\
\hline 11 & (11) Running 800m/1500m (s) & 0.80 & 0.73 \\
\hline 12 & (12) Vital capacity (1) & 0.88 & 0.70 \\
\hline 13 & (13) Cardiac Function (Hw) & 0.81 & 0.79 \\
\hline 14 & (14) Test Tapping (đ) & 0.86 & 0.69 \\
\hline 15 & (15) LanDolt Open Loop (bit/s) & 0.81 & 0.74 \\
\hline
\end{tabular}


Table 10. Tests for reliability and informability of tests on female students $(\mathrm{n}=30)$

\begin{tabular}{|c|c|c|c|}
\hline \multirow{2}{*}{ No } & Test & \multicolumn{2}{|c|}{$\mathbf{R}$} \\
\cline { 3 - 4 } & & $\mathbf{r}_{\mathbf{t t}}$ & $\mathbf{r}_{\mathbf{t c}}$ \\
\hline 1 & Standing height (cm) & 0.81 & 0.72 \\
\hline 2 & Weight $(\mathrm{kg})$ & 0.82 & 0.70 \\
\hline 3 & BMI & 0.88 & 0.64 \\
\hline 4 & Lie on your back with sit-ups/30s & 0.82 & 0.78 \\
\hline 5 & (times) & 0.84 & 0.72 \\
\hline 6 & Hand grip force (KG) & 0.85 & 0.80 \\
\hline 7 & Jump away in place (cm) & 0.92 & 0.88 \\
\hline 8 & Long jump (cm) & 0.91 & 0.88 \\
\hline 9 & Shuttle Running 4x10m(s) & 0.85 & 0,82 \\
\hline 10 & Running $30 \mathrm{~m}(\mathrm{~s})$ & 0.93 & 0.85 \\
\hline 11 & Running 800m/1500m(s) & 0.84 & 0.78 \\
\hline 12 & Vital capacity (l) & 0.82 & 0.71 \\
\hline 13 & Cardiac Function (Hw) & 0.85 & 0.75 \\
\hline 14 & Test Tapping (d) & 0.88 & 0.73 \\
\hline 15 & LanDolt Open Loop (bit/s) & 0.89 & 0.82 \\
\hline
\end{tabular}

The results in Table 7 and 8 show that, 15/15 selected tests are reliable and informed on research subjects. Thus, through the practical testing to determine the reliability and informability and of the above tests with the research subjects, the topic has selected 15 tests (including aspects: morphology, fitness, physiological and psychological) to apply, test and assess the physical capacity of HCMC UTE students.

\section{Discussion}

There are many studies in the world that have been interested in the issue of physical assessment for students. According Alabama Department of Education [ALSDE], standards at state and national levels stress the importance of ensuring students achieve and maintain a health-enhancing level of physical fitness [12]. American Alliance for Health, Physical Education, Recreation, and Dance [AAHPERD] has been concluded that execution of the physical fitness assessment process includes following developmentally appropriate and educationally sound practices [13].

In fact, these tests are quite routine and have been used quite a lot in sports science practice. Currently, countries around the world and in the Asian region have developed specific standards to assess physical fitness for adolescents, specifically as follows:

The European Community uses the following tests: Jump away in place $(\mathrm{cm})$; hanging on the bar in the position of arms bent (s); Lying on the back with sit-ups for 30s (times); Hand squeeze force (KG); Running shuttle $10 \times 5 \mathrm{~m}$ (s); Cross arms on the table 25 times (s); Running the shuttle to accelerate on a distance of $20 \mathrm{~m}$ (counting the number of times to pass 20m); PWC 170; Sitting with arms folded in front $(\mathrm{cm})$; Balance standing on one leg (second) [4].

The US uses the following tests: Jump away in place $(\mathrm{cm})$; Running of 50 yards (s); Shuttle run $4 \times 10$ yards combined with picking up 2 objects (s), running or walking 400 yards (s); Pulling up bar (times); Liying on your back; Bending your stomach with the maximum number of times.

Russia uses the following tests to assess the fitness of students aged 5-17: Pulling the barbell (times) for men; Hanging with the arms bent over the bar (s) for women; Jump away in place $(\mathrm{cm})$, Shuttle running $5 \times 10 \mathrm{~m}(\mathrm{~s})$; Running $1000 \mathrm{~m}(\mathrm{~s})$, Standing flexible bending body $(\mathrm{cm})$, Lie on your back with sit-ups/30s (times).

Japan uses the following tests Jump away in place (cm); Lie on your back with sit-ups/30s (times); Lying on your stomach doing push-ups (times); Shuttle 5m running for 15 seconds (m); Running for 5 minutes depending on your strength $(\mathrm{m})$.

Thailand's fitness assessment includes tests: Hand grip force $(\mathrm{KG})$; Lie on your back with sit-ups/30s (times); Shuttle running $4 \times 10 \mathrm{~m}(\mathrm{~s})$; Sitting upright with legs bent forward $(\mathrm{cm})$, running $500 \mathrm{~m}(\mathrm{~s})$, lie on your stomach with your arms bent $20 \mathrm{~cm}$ off the ground for men (times); Hanging with the arms bent over the bar (s) for women.

In Vietnam, there are also studies that have used similar tests to assess the fitness level of university and college students, but the number and nature of these tests are not consistent, comprehensive and quite scattered [4].

\section{Conclusions}

Through reference to scientific works published in Vietnam as well as abroad, the topic has synthesized 53 tests (12 morphological tests; 24 physical tests; 10 physiological tests and 7 psychological tests) to included in the selection of students' physical fitness assessment and classification. On the basis of synthetic tests and following the selection principles, the study has omitted complicated and less common exercises, leaving 41 tests to include in the expert interview step.

Finally, the topic has selected 15 tests that satisfy the conditions as convention, as well as ensure reliability and informability for inclusion in the physical assessment test of HCMC UTE students. There are 03 morphological tests [Standing height $(\mathrm{cm})$, Weight $(\mathrm{kg}), \mathrm{BMI}$; 08 fitness tests [Lying on your back with sit-ups/30s (times), Standing flexible bending body $(\mathrm{cm})$, Hand grip force (KG), Jump away in place $(\mathrm{cm})$, Long jump $(\mathrm{cm})$, Running $4 \times 10 \mathrm{~m}(\mathrm{~s})$, Running $\quad 30 \mathrm{~m} \quad(\mathrm{~s}), \quad$ Running $\quad 800 \mathrm{~m} / 1500 \mathrm{~m}(\mathrm{~s}) ; 02$ physiological tests [Vital capacity (1), Cardiac function $(\mathrm{Hw})] ;) ; 02$ psychological tests [Test Tapping (e), 
LanDolt Open Loop (bit/s)].

\section{Acknowledgments}

This research is supported by Ho Chi Minh City University of Technology and Education (Vietnam). We thank our colleagues from the Department of Science and Technology for providing insight and expertise and providing great support to the study, even though they may not agree with all of the best views, interpretations, and interpretations.

\section{REFERENCES}

[1] Le Quang Anh, "Research on building a scale to assess the physical development of male and female students at Can Tho University", Master thesis, 2005, pp. 118-125.

[2] Viet Nam Ministry of Education and Training, Decision No. 53/2008/QD-BGDDT, Promulgating Regulations on assessment and classification of students' physical fitness, dated September 18, 2008.

[3] Duong Nghiep Chi, Tran Duc Dung, Ta Huu Hieu, Nguyen Duc Van, "Sports Measurement", Sports Publishing House, 2004, pp. 58-67.

[4] Le Van Lam, Pham Trong Thanh, Physical education in some countries around the world, Sports Publishing House, 2000, pp. 111-128.

[5] Truong Hong Long, "Building standards to assess physical development for students at Quy Nhon University", Master thesis, 2005, pp. 98-118.

[6] Nguyen Thai Sinh, "Study to develop standards for assessing the level of physical preparation of students at Hue University", Doctoral Thesis in Education, 2003, pp. 122-131.

[7] Vo Van Vu, "Assessment of the current situation and solutions to improve the effectiveness of physical education and sports activities in high schools in Da Nang", Doctoral thesis in Educational Science, Institute of Sports Science, 2014, pp. 94-117.

[8] Ahmet Sadan Okmen, Evaluation of the physical education and sports curriculum in Turkish schools, Academic Journals Vol. 12(16), pp. 811-816, 23 August, 2017. DOI:10.5897/ERR2017.3303

[9] ROTC Physical Fitness Assessment (PFA), "The Army Physical Fitness Test (APFT), and Required Height/Weight Information", 2013, pp. 1-6. https://www.goarmy.com/con tent/dam/goarmy/downloaded_assets/pdfs/hs-scholarship-p hysical-assessment-17.pdf.

[10] Griffin, P., \& Care, E. (Eds.). Assessment and teaching of 21st century skills: Methods and approach. Springer. 2014.

[11] Nedal Ahmad Alghafary, "The Availability of the 21st Century Skills in the Sport and Health for All Curriculum of the Undergraduate University Students in Al-Balqaa Applied University, Jordan," International Journal of Human Movement and Sports Sciences, Vol. 8, No. 5, pp. 217 - 228, 2020. DOI: 10.13189/saj.2020.080509.

[12] Hill, Kory and Thornburg, Roland "Developing Effective Physical Fitness Testing Standards for Pre Service Physical Educators," Networks: An Online Journal for Teacher Research: Vol. 18: Iss. 2, 2016. https://dx.doi.org/10.4148/2470-6353.1004

[13] Lenny D. Wiersma \& Clay P. Sherman, "The Responsible Use of Youth Fitness Testing to Enhance Student Motivation, Enjoyment, and Performance", Measurement in Physical Education and Exercise Science, 12:3, 167-183, 2008. DOI: $10.1080 / 10913670802216148$ 